\title{
FUZZY AND BOOLEAN FOREST MEMBERSHIP: ON THE ACTUAL SEPARABILITY OF LAND COVER CLASSES
}

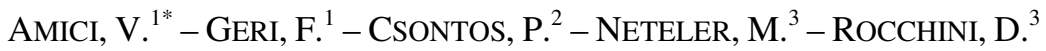 \\ ${ }^{1}$ Dipartimento di Scienze Ambientali "G. Sarfatti”, Università di Siena, via P.A. Mattioli 4, \\ 53100, Siena, Italy \\ ${ }^{2}$ Res. Inst. for Soil Science and Agricultural Chemistry, Herman O. út 15., Budapest, H-1022, \\ Hungary \\ ${ }^{3}$ IASMA Research and Innovation Centre, Fondazione Edmund Mach, Environment and \\ Natural Resources Area, Via E. Mach 1, 38010 S. Michele all'Adige, TN, Italy \\ *Corresponding author \\ e-mail: valerio.amici@tele2.it \\ (Received $5^{\text {th }}$ February 2010 ; accepted $3^{\text {rd }}$ March 2010)
}

\begin{abstract}
Forests are among the most important habitats of the Earth for several ecological reasons and their management is a prior task when dealing with landscape conservation. Thematic maps and remote sensing data are powerful tools to be used in landscape planning and forest management; nevertheless, most of the European and Mediterranean forest monitoring and conservation programs do not take into account the continuity of the variation of habitats within the landscape but they only rely on boolean classification methods. The utilisation of a classification method that applies a continuity criterion is fundamental because it is expected to better represent the ecological gradients within a landscape. The aim of this paper is to assess the amount of classification uncertainty related to crisp (boolean) classes, particularly focusing on forest identification uncertainty. Forest fuzzy membership of the Tuscany region (Italy) derived from a Landsat ETM+ image scene was compared with the widely used crisp datasets in European forests management and conservation practices, i.e. the European JRC Forest/Non-Forest map, the CORINE Land Cover 2000 (levels 1 and 2), as well as the Global Land Cover 2000, in order to qualitatively and quantitatively assess the separability of crisp classes with respect to forest fuzzy membership. A statistically significant $(\mathrm{p}<0.001)$ forest fuzzy membership separability among the considered crisp classes was found. Despite the crisp dataset and hierarchical level taken into account, both forest and non-forest crisp classes showed a high degree of forest fuzzy membership variability. Therefore, given the intrinsic mixture of crisp land cover classes, ecological studies on forestal ecosystems should rigorously take into account the classification uncertainty related to a crisp view of ecological entities which are being mapped.
\end{abstract}

Keywords: biodiversity, classification uncertainty, forest conservation, forest management, fuzzy set theory, remote sensing

\section{Introduction}

Forests represent one of the most important habitats on Earth for several ecological reasons, including: hosting a great amount of Earth's biodiversity (Sohngen et al., 1999); preventing soil erosion; replenishing ground water by reducing water runoff; controlling flooding; enhancing infiltration; and storing carbon (Perry 1994; Oren et al., 2001).

Forest fragmentation represents one of the crucial phenomena responsible for global decline of biodiversity (Wilcox and Murphy 1985), particularly in the Mediterranean biome where a high amount of native forest has been converted (Hoekstra et al., 2005). In order to protect forests, several international programs were drawn up in The Convention on Climate Change, Convention on Biological Diversity and Ministerial Conference on the Sustainable Forest Management (McRoberts and Tomppo, 2007).

APPLIED ECOLOGY AND ENVIRONMENTAL RESEARCH 8(1): 39-50. http://www.ecology.uni-corvinus.hu • ISSN 15891623 (Print) • ISSN 17850037 (Online) (c) 2010, ALÖKI Kft., Budapest, Hungary 
As firstly recognised by Wulder (1998) and further reinforced by McRoberts and Tomppo (2007), the efficiency of forest management could be improved if forest planners and managers would apply remote sensing data. In this view, thematic maps (e.g. land cover, forest cover, forest habitats) are being increasingly used in landscape planning and management (Kepner et al., 2000; Butler et al., 2004; Romero-Calcerrada and Perry, 2004; Acosta et al., 2005; Rocchini et al., 2006). Typically, thematic maps are derived from both classification of remotely sensed images and from data analysis in geographic information system (GIS) technology (Gopal and Woodcock, 1994). In a classical land cover map, a polygon or a pixel can describe only a single land cover category applying a boolean membership in the integer set $\{0,1\}$; thus, the degree to which it is in reality mixed cannot be differentiated (Rocchini and Ricotta, 2007). On the contrary, fuzzy set theory allows map producers to maintain uncertainty information of each class by taking into account the gradual change from class membership to nonmembership (Gopal and Woodcock, 1994). The fuzzy membership function $\mu$ associates for each entity (a polygon or a pixel) a membership level $\mu_{\mathrm{c}}$ in the range 0 to 1 expressing the possibility that a given entity (i.e. a polygon or a pixel) belongs to the thematic map class $c$ (see Zadeh, 1978). Several studies have used fuzzy set theory for forest mapping (see e.g. Maselli et al., 1995; Zadnik Stirn, 2006) proving its efficiency in discriminating forest versus non-forest areas applying a continuity criterion which seems to better represent ecological gradients within a landscape. However, most of the European and Mediterranean forest monitoring and conservation programs (e.g. European Forest Monitoring Programme, Forest Focus, ICP forests) rely only on crisp classified land cover maps. In this paper, we consider European land cover projects such as the CORINE Land Cover 2000 (EEA 2005a, Neumann et al., 2007), the Global Land Cover (GLC2000, Bartholomé and Belward, 2005) and the JRC Forest/Non-forest (Pekkarinen et al., 2007), which seem to produce the mostly used data for both research and management of forest ecosystems.

The aim of this paper is to assess the amount of classification uncertainty related to crisp classes, particularly focusing on forest mapping uncertainty. In particular we will quantitatively assess (i) the separability of boolean classes with respect to forest fuzzy class membership $\left(\mu_{\mathrm{f}}\right)$, and (ii) the amount of $\mu_{\mathrm{f}}$ inner variability of each crisp land cover class.

\section{Materials and methods}

\section{Study area}

The study area is the Tuscany region (Italy, $42^{\circ}-44^{\circ}$ north latitude, $9^{\circ}-12^{\circ}$ east longitude, WGS84, 3,464 km², Fig. 1), a typical Mediterranean ecosystem, including forests at various altitudinal locations. Currently, the surface of the region is predominantly occupied by agricultural areas (55\% of the surface), while the wooded areas occupy $34 \%$ of the territory. Besides conifer plantations which are scattered throughout the whole region, broadleaf forests vary from the evergreen Mediterranean forests dominated by Quercus ilex, along the coastlines, to the Fagus sylvatica and Abies alba forests of mountain sites (see e.g. Chiarucci and Bonini, 2005; Rocchini, 2007). 

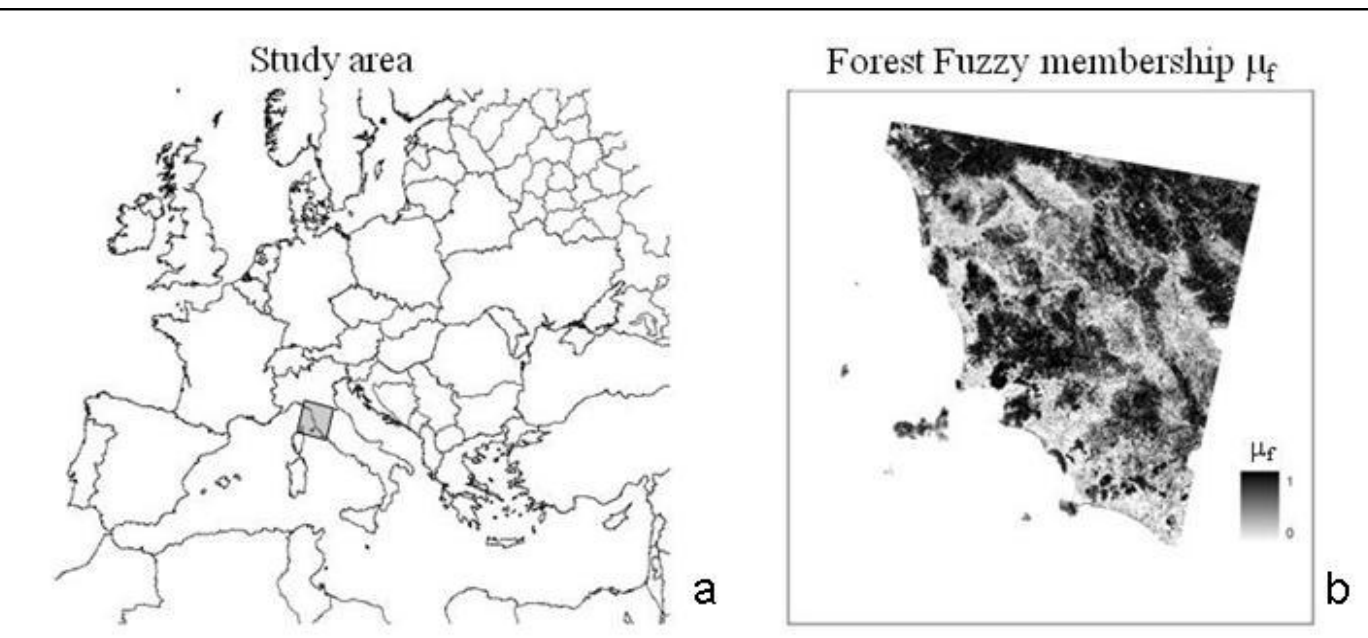

\section{JRC Forest/Non Forest}

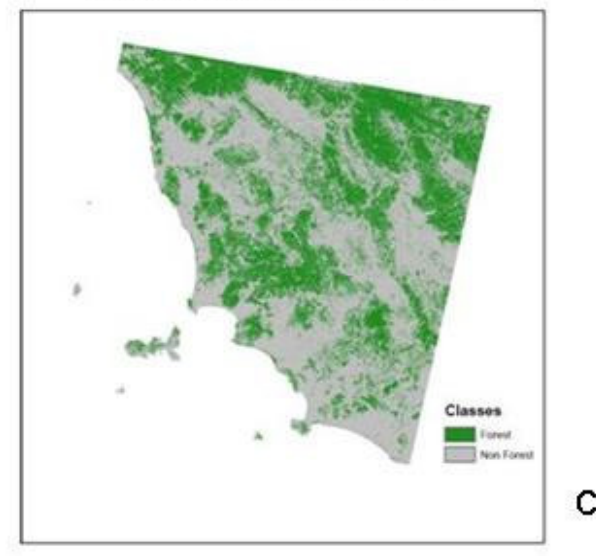

CORINE Land Cover (level 1)

CORINE Land Cover (level 2)

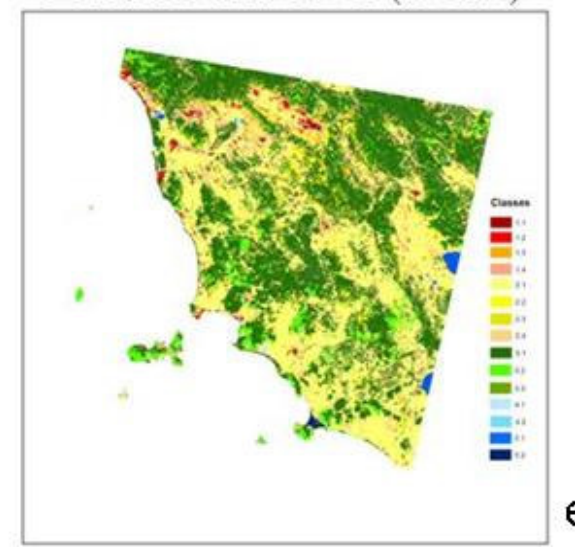

e

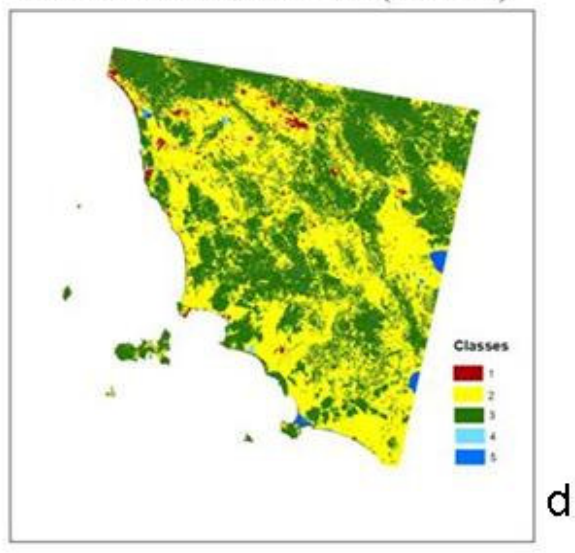

Global Land Cover 2000

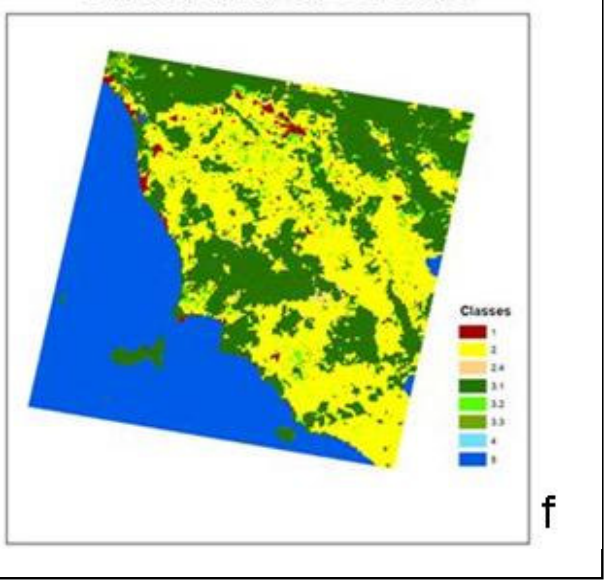

Figure 1. Study area (a) and the used datasets:

(b) Forest fuzzy membership $\mu_{f}$; (c) JRC Forest/Non-forest map; (d) CORINE Land Cover 2000 level 1; (e) CORINE Land Cover 2000 level 2; $(f)$ GLC2000, rearranged according to the CORINE Land Cover dataset. See Table 1 for the classes description 


\section{Landsat ETM+ data set and forest fuzzy classification}

An ortho-rectified Landsat ETM+ image (path 192, row 030, acquisition date June 20, 2000, spatial resolution 30 metres in the optical/near infrared channels) was acquired. The bands used were: band 1 (blue, $0.45-0.515 \mu \mathrm{m}$ ), band 2 (green, $0.525-$ $0.605 \mu \mathrm{m}$ ), band 3 (red, $0.63-0.69 \mu \mathrm{m}$ ), band 4 (near infrared, $0.75-9.90 \mu \mathrm{m}$ ), band 5 (middle infrared, $1.55-1.75 \mu \mathrm{m}$ ) and band 7 (middleinfrared, $2.09-2.35 \mu \mathrm{m}$ ). Band 6 was not considered due to the much larger pixel size than the other bands (60 meters of ground resolution opposed to 30 meters of the other bands).

In order to perform forest fuzzy classification, we applied a supervised classification approach by selecting known forest training sites (including both broadleaf and conifer plantations) within the image, based on field data acquired in previous research in Tuscany (Chiarucci et al., 2001; Chiarucci and Bonini, 2005; Rocchini, 2007).

A fuzzy soft classifier was applied using the software Idrisi (FUZCLASS module, Eastman, 2006). Fuzzy membership is based on the distance of each pixel to the mean reflectance of each band for a training class signature. To accommodate quality of training signatures and width of classes, the Z-score (standard deviation units) at which a fuzzy set membership decreases to zero was set to $\sim 2$ by trial and error procedure (Eastman, 2006). In this paper, we will refer to forest fuzzy membership to as $\mu_{\mathrm{f}}$.

\section{European land cover crisp data sets}

\section{CORINE Land Cover 2000 dataset (levels 1 and 2)}

The CORINE Land Cover project is a regional program in which the datasets have been created under the responsibility of each EU member state based on interpretation and digitisation of Landsat images (Landsat ETM+, with a resolution of $30 \mathrm{~m}$ ) in a GIS environment (Bossard et al., 2000). The CORINE nomenclature comprises 44 land cover classes (at level 3), but in this paper we considered only levels 1 and 2 (5 and 15 classes, respectively; Table 1, Fig. 1). More specific levels like level 3 should allow to discriminate broadleaf from coniferous forests. However, as previously stated, the training sites for building the forest fuzzy map included both broadleaf forests and coniferous plantations, thus forcing us to choose higher CORINE hierarchical levels (i.e. a more generalised CORINE crisp classification) for performing further analysis (Table 1). We used the vector format dataset with a minimum mapping unit of 25 ha (EEA, 2005b).

\section{Global Land Cover 2000 dataset (GLC2000)}

The GLC2000 map (also developed by the JRC) covers the whole globe and uses the United Nations land cover classification system. It is based on Spot-Vegetation satellite images (with a spatial resolution of $1 \mathrm{~km}$ ). This dataset was produced by harmonizing and merging the individual national products to one global product with a generalised legend (23 classes, see Bartholomé and Belward, 2005). In order to assure comparability, in this paper the codes of GLC2000 classes were rearranged according to the CORINE Land Cover classes scheme. Strictly spoken, the nearest CORINE class code was attributed to each GLC2000 class despite the CORINE level (Table 1, Fig. 1). 
Table 1. Crisp land cover classes for each dataset considered in this paper: CORINE Land Cover 2000 (levels 1 and 2), GLC2000, JRC. Notice that GLC2000 classes were rearranged according to the CORINE Land Cover dataset for comparability purposes. The number of points falling within each class is reported (total number of pixels $=6706$ ).

\begin{tabular}{|c|c|c|}
\hline Dataset & Code numbers and names of land cover classes & $\begin{array}{c}\text { Number of } \\
\text { points }\end{array}$ \\
\hline \multirow[t]{5}{*}{ CLC2000 (level 1) } & $1-$ Artificial Surfaces & 232 \\
\hline & 2 - Agricultural areas & 3405 \\
\hline & 3 - Forest and semi-natural areas & 2996 \\
\hline & $4-$ Wetlands & 10 \\
\hline & 5- Water Bodies & 63 \\
\hline \multirow[t]{15}{*}{ CLC2000 (level 2) } & 1.1 - Urban Fabric & 154 \\
\hline & 1.2 - Industrial, commercial and transport units & 49 \\
\hline & 1.3 - Mines, dumps and construction sites & 20 \\
\hline & 1.4-Artificial non agricultural vegetated areas & 9 \\
\hline & $2.1-$ Arable land & 1831 \\
\hline & 2.2 - Permanent crops & 377 \\
\hline & $2.3-$ Pastures & 221 \\
\hline & $2.4-$ Heterogeneous agricultural areas & 976 \\
\hline & $3.1-$ Forest & 2657 \\
\hline & 3.2 - Scrub and/or herbaceous vegetation associations & 322 \\
\hline & 3.3 - Open spaces with little or no vegetation & 17 \\
\hline & 4.1 - Inland wetlands & 9 \\
\hline & 4.2 - Coastal wetlands & 1 \\
\hline & 5.1 - Continental waters & 53 \\
\hline & $5.2-$ Marine waters & 10 \\
\hline \multirow[t]{12}{*}{ GLC2000 } & 1 - Artificial surfaces and associated areas & 123 \\
\hline & 2 - Cultivated and managed areas & 2994 \\
\hline & 2.4 - Mosaic: Cropland/Shrub and/or grass cover & 61 \\
\hline & 3.1 - Tree Cover, broadleaved, deciduous, closed & 1705 \\
\hline & 3.1 - Tree Cover, mixed leaf type & 778 \\
\hline & 3.1 - Tree Cover, needle-leaved, evergreen & 81 \\
\hline & 3.2 - Herbaceous Cover, closed-open & 282 \\
\hline & 3.2 - Shrub Cover, closed-open, deciduous & 354 \\
\hline & 3.2 - Shrub Cover, closed-open, evergreen & 211 \\
\hline & $3.3-$ Bare areas & 43 \\
\hline & 4- Regularly flooded shrub and/or herbaceous cover & 2 \\
\hline & $5-$ Water bodies & 72 \\
\hline \multirow[t]{2}{*}{ JRC Forest } & Forest & 2562 \\
\hline & Non forest & 4144 \\
\hline
\end{tabular}

\section{JRC Forest/Non-forest dataset}

The Pan-European Forest/Non-forest map (Pekkarinen et al., 2007) developed by the Joint Research Centre (JRC, Fig. 1) is based on Landsat ETM+ imagery with original spatial resolution of $30 \mathrm{~m}$, subsequently resampled to $25 \mathrm{~m}$ with the scope of 
representing the forested area extent of the year 2000. The land cover information used for the forest mapping originates from the CORINE Land Cover 2000 (hereafter simply referred to as CORINE Land Cover). The categories constituting this map, related to main land cover classes are: 1-Forest, 2-Non Forest, 3-Clouds or snow (no data).

All the forest classes are defined as areas occupied by forest and woodlands with a vegetation pattern composed by native or exotic coniferous and/or broad-leaved trees. We refer to the JRC Pan-European Forest Mapping website (http://forest.jrc.it/ForestResources) for a complete description of those vegetation types included into the forest class.

\section{Statistical analysis: testing crisp classes separability}

Ten thousand random points were selected within the Landsat ETM+ image extent. Of these, 3294 points falling within the sea were not considered since the interest was focused on terrestrial ecosystems. Forest fuzzy membership $\mu_{\mathrm{f}}$ values were attributed to each of the 6706 random points. The random points were labelled with each crisp class of each land cover dataset: JRC, CORINE Land Cover 2000 (levels 1 and 2), and GLC2000. Thus, a box-plot of forest fuzzy membership $\mu_{\mathrm{f}}$ vs. classes for each land cover dataset was built in order to qualitatively assess the separability of crisp classes with respect to $\mu_{\mathrm{f}}$. The whole procedure was repeated considering different land cover classifications (CORINE Land Cover 2000, GLC2000, JRC,) and thematic levels. In this paper, we refer to thematic level as the hierarchical classification level of CORINE Land Cover data set.

In order to quantitatively test for $\mu_{\mathrm{f}}$ separability of crisp classes considering each land cover dataset, a Kruskal-Wallis non-parametric test (Zar, 1996) was performed within the $\mathrm{R}$ statistical language software ( $\mathrm{R}$ Development Core Team, 2007). The $\mathrm{H}_{0}$ hypothesis to be tested was that the mean of forest fuzzy membership values is the same in each group (class) and is tested by a rank sum test. We refer to Rogerson (2001) for an analytical dissertation on the matter.

\section{Results and discussion}

Considering the CORINE Land Cover level 1, the land cover classes were statistically different $(\mathrm{p}<0.001)$ with respect to $\mu_{\mathrm{f}}$ (Table 2$)$; particularly class 3 ("Forest and semi-natural areas") showed higher $\mu_{\mathrm{f}}$ values (Fig. 2).

Table 2. Separability of crisp land cover classes with respect to forest fuzzy membership tested by Kruskal-Wallis non-parametric test.

\begin{tabular}{|l|c|c|c|}
\hline \multicolumn{1}{|c|}{ Dataset } & Chi-squared & df & p-value \\
\hline CORINE Land Cover level 1 & 2767.85 & 4 & $<0.001$ \\
\hline CORINE Land Cover level 2 & 2969.31 & 14 & $<0.001$ \\
\hline GLC2000 & 1621.47 & 7 & $<0.001$ \\
\hline JRC & 2829.99 & 1 & $<0.001$ \\
\hline
\end{tabular}




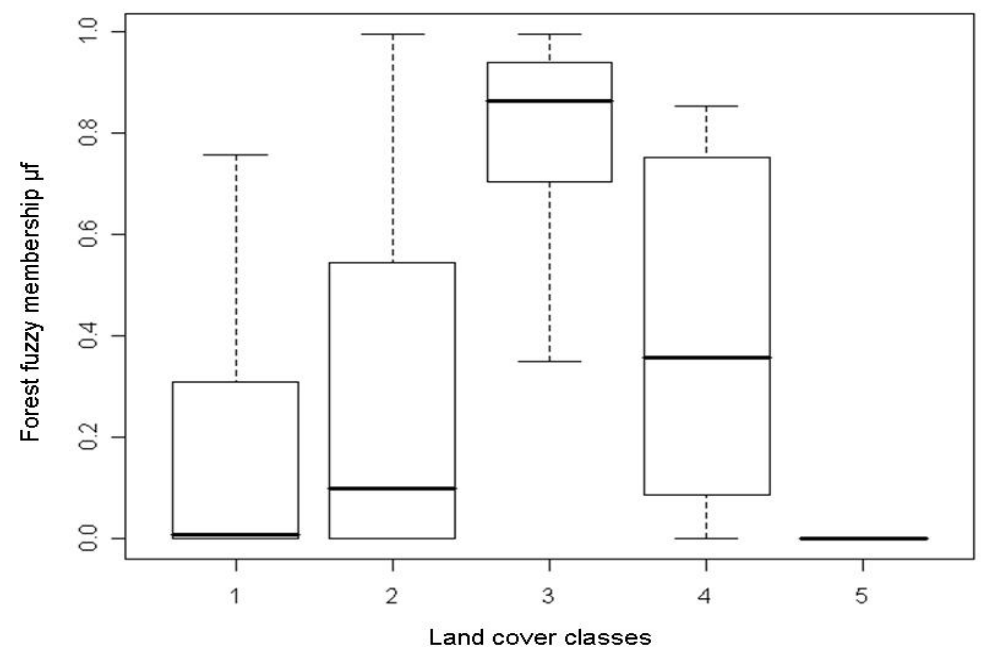

Figure 2. Box-plot of forest fuzzy membership $\mu_{f}$ versus CORINE Land Cover classes (level 1). See Table 1 for the classes description and the legend of Fig. 2 for the description of box-plot graphical representation.

High $\mu_{\mathrm{f}}$ values were detected for wetland areas (class 4) where shrublands and riparian tree vegetation (dominated by Populus and Salix genera) should have led to an increased $\mu_{\mathrm{f}}$ value (considering both median and variability towards higher $\mu_{\mathrm{f}}$ values). Variability in lower $\mu_{\mathrm{f}}$ values is presumably related to the presence of shallow water. We refer to Rocchini et al. (2005) and Laba et al. (2008) for major details on spectral behaviour of wetland vegetation and its classification.

Agricultural areas (class 2) showed low values approaching 0.1 but with a high variability reaching maximum $\mu_{\mathrm{f}}$ values mainly related to tree crops (fruit, olive plantations, etc). Urban areas (class 1) and water (class 5) showed $\mu_{\mathrm{f}}$ values approaching zero, with a high and very low variability, respectively. The high $\mu_{\mathrm{f}}$ variability of urban areas is probably due to urban parks and isolated trees (La Sorte and McKinney, 2006; Ricotta et al., 2001).

The same general pattern was found for the CORINE Land Cover level 2 (Fig. 3) with classes being statistically different $(\mathrm{p}<0.001)$ to each other (Table 2$)$. For a major comprehension of the achieved results (Fig. 3), we will discuss CORINE Land Cover level 2 from urban areas (classes starting with code 1) to water (classes starting with code 5).

Urban fabric and industrial units (classes 1.1 and 1.2) showed low median values. Surprisingly, both mines and artificial non agricultural vegetated areas $(1.3,1.4)$ showed higher $\mu_{\mathrm{f}}$ values approaching 0.3 with a high variability. Nonetheless, it should be stressed that the number of points falling within such classes was quite low (20 and 9 respectively, Table 1). Thus it is hypothesised that the low number of points should hamper to completely evaluate actual $\mu_{\mathrm{f}}$ median and variability values. Considering arable land, all classes (2.1- Arable land, 2.2 - Permanent crops, 2.3 - Pastures, 2.4 Heterogeneous agricultural areas) showed low $\mu_{\mathrm{f}}$ values ranging from ca. 0.03 to 0.2 with variability being probably dependent of orchard areas. 


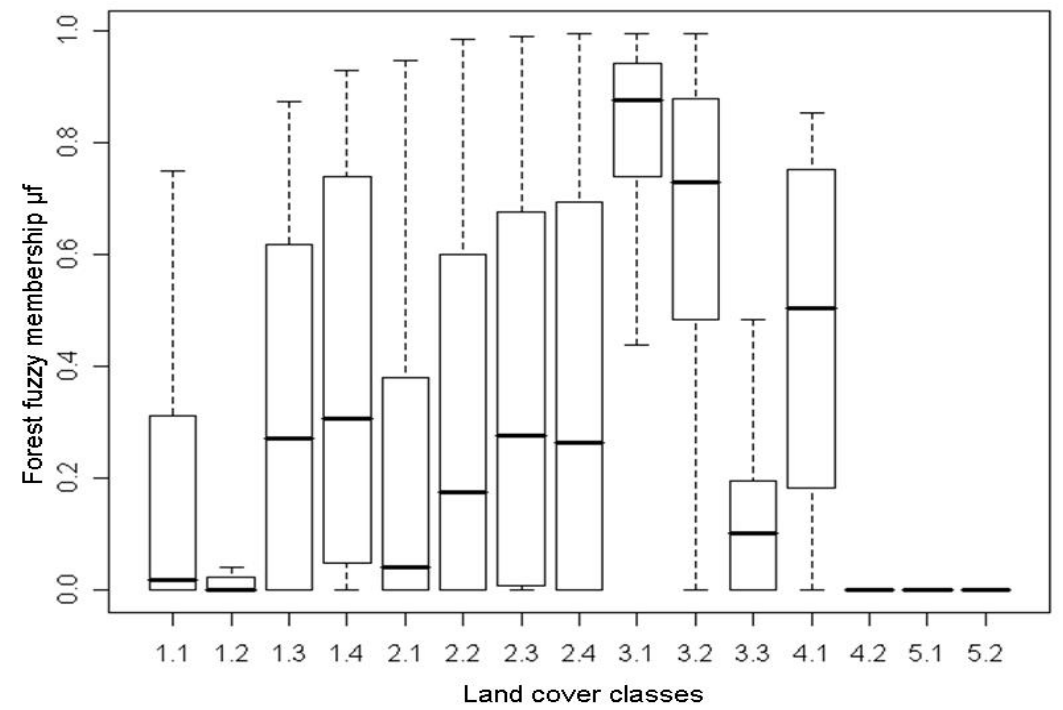

Figure 3. Box-plot of forest fuzzy membership $\mu_{f}$ versus CORINE Land Cover classes (level 2). See Table 1 for the classes description and the legend of Fig. 2 for the description of box-plot graphical representation.

Once forests and semi-natural areas (level 1, class 3) were divided into more detailed classes, forests (class 3.1) showed highest $\mu_{\mathrm{f}}$ values. Meanwhile, considering their variability, low values were achieved approaching the value 0.4. Scrub and/or herbaceous vegetation associations (class 3.2 ) showed intermediate median values with a high variability spanning the whole $\mu_{\mathrm{f}}$ range, while open spaces (class 3.3) showed low median values with variability standing at the low $\mu_{\mathrm{f}}$ values. As previously stated for wetlands (level 1, class 4) inland wetlands (4.1) showed median values approaching 0.5 and a high variability mainly due to riparian vegetation. On the contrary, coastal wetlands (4.2) showed a low value related to a single point falling within this class (Table 1).

Water classes, both continental (class 5.1) and marine (class 5.2), showed $\mu_{\mathrm{f}}$ values approaching 0 with very low variability as found considering the CORINE Land Cover level 1.

Considering the GLC2000 dataset rearranged with the CORINE Land Cover level 1 and 2 legend, while the same general pattern of the CORINE Land Cover level 1 and 2 was observed (Table 2, Fig. 4), some differences were detected. As an example, wetland areas (class 4) showed $\mu_{\mathrm{f}}$ values higher than those of forests (class 3.1). However, it should be noticed that class 4 was represented by only regularly flooded shrub and/or herbaceous cover thus increasing $\mu_{\mathrm{f}}$ median values, and only two points fell within this class (Table 1). The forest map result of fuzzy classification performed through the selected 6 Landsat ETM+ bands used is shown in Fig. 1. 


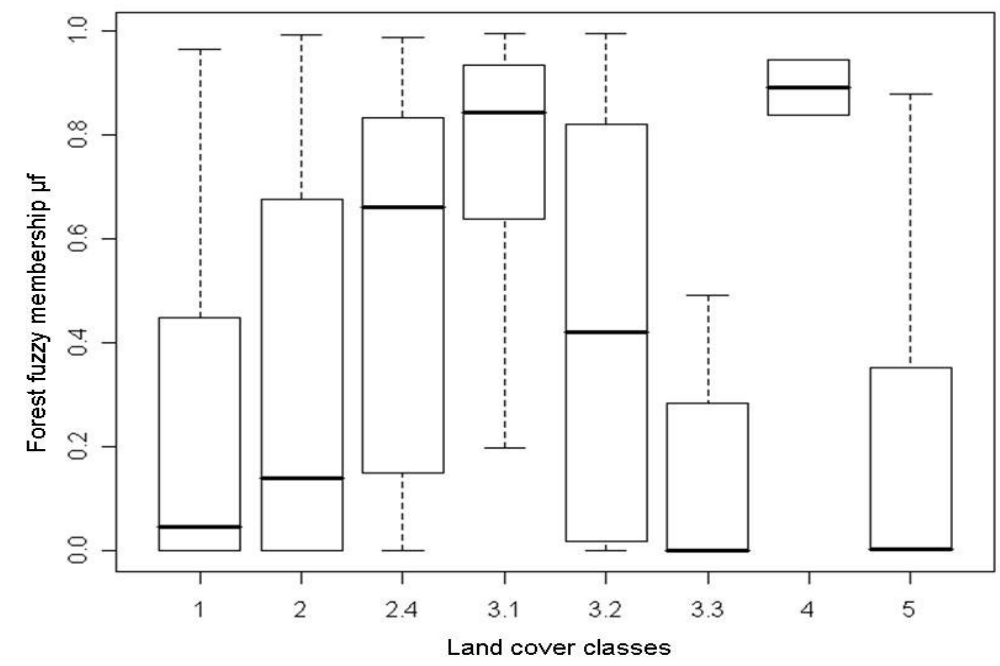

Figure 4. Box-plot of forest fuzzy membership $\mu_{f}$ versus GLC2000 classes. Notice that codes were assigned according to the CORINE Land Cover thematic legend. See Table 1 for the classes description and the legend of Fig. 2 for the description of box-plot graphical representation.

The JRC dataset showed a statistically significant separability $(\mathrm{p}<0.001)$ of forest fuzzy membership $\mu_{\mathrm{f}}$ between forest versus non-forest classes (Table 2), with forest class showing higher values with respect to non-forest class, as expected (Fig. 5). The lower $\mu_{\mathrm{f}}$ values variability of forests should be related to substantial landscape homogeneity of this class within the Tuscany region.

In this paper, fuzzy classification was applied only to forest mapping (i.e. forest fuzzy membership) in order to assess the amount of variability which is lost by using crisp sets for forests identification within a landscape. We focused on only one Landsat ETM+ image scene within a typical Mediterranean area such as the Tuscany region, on the strength of its high landscape variability (Rocchini, 2007), in order to stress the whole analysis on a high level of uncertainty in forest identification to deal with. However, this should not hamper to translate the achieved results to other types of landscapes or thematic classes.

The considered crisp datasets showed statistically significant $\mu_{\mathrm{f}}$ separability. However, despite the hierarchical level being taken into account, both forest and nonforest crisp classes showed a high degree of inner $\mu_{\mathrm{f}}$ variability (uncertainty). Focusing on forest classes, $\mu_{\mathrm{f}}$ reached in some cases low ( 0.4, see e.g. Fig. 3 and 4$)$ to very low values ( 0.2, see e.g. Fig. 5). Two main reasons could be advocated for: (i) scale matching problems associated with different spatial resolutions (Jelinski and Wu, 1996), (ii) the intrinsic mixing of crisp land cover classes (Small, 2004).

As stressed by Arbia et al. (1998), one of the main problems when dealing with digital representation of geographic entities is linked to the discrepancy between the digital GIS representation of spatial objects and the real entities they are seeking to describe. In particular, it is worth recalling that results of the analyses for the same area can vary because of the spatial resolution (Johnson and Howarth, 1987), and that some patterns or processes can be recognised only at appropriate resolution (Jelinski and $\mathrm{Wu}$, 
1996). An ecological phenomenon or a spatial entity may remain undetected because of an improper matching with the scale of analysis (Stohlgren et al., 1997). Therefore, scale mismatching may hamper the comparison of spatial entities with different resolutions. As an example, it is expected that a polygon layer with a minimum mapping unit of 25 ha (as that of the CORINE Land Cover) or a raster layer with a pixel resolution of $1 \mathrm{~km}$ (such as that of the GLC2000) should thematically match the Landsat ETM+ pixel of $30 \mathrm{~m}$.

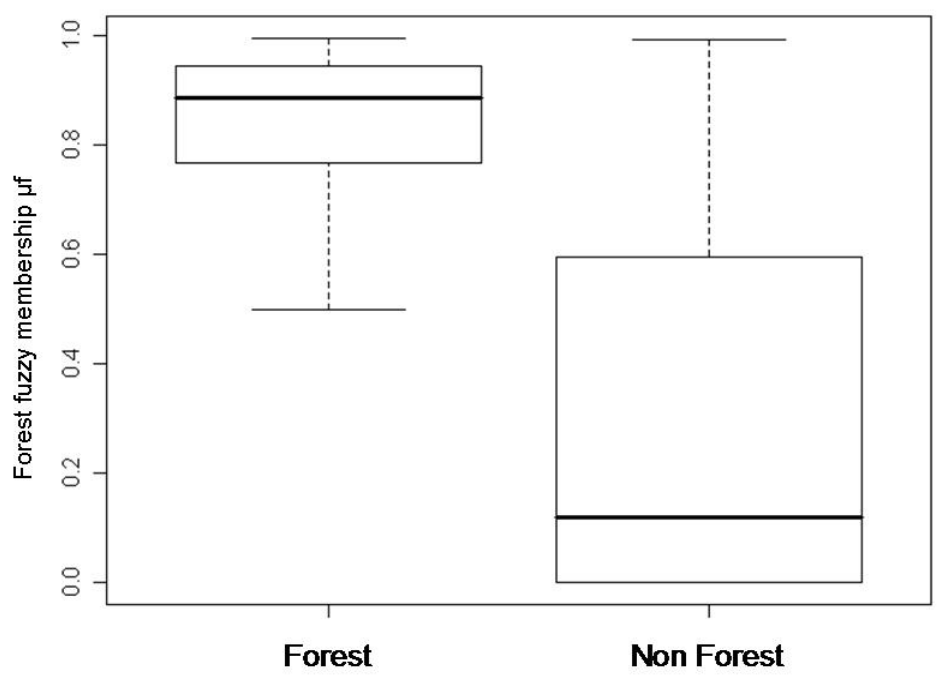

Figure 5. Box-plot of forest fuzzy membership $\mu_{f}$ versus JRC Forest/Non-forest classes. The box represents the middle 50\% of the data, the upper and lower parts of the box indicate the 75th and 25th percentile of the data, respectively. The line in the box indicates the median value of the data and the length of the bars indicate 1.5 times the inter-quartile distance.

Spatial resolution has impact on the thematic resolution of the represented entities (Burrough and McDonnell, 1998; Nagendra and Rocchini, 2008). In fact, more detailed crisp classes can be represented only at higher spatial resolution with smaller spatial objects (e.g. hedgerows), while a higher degree of spectral mixing and inner thematic uncertainty is expected when objects (both polygons and pixels) become bigger.

\section{Conclusion}

In this paper, we demonstrated that crisp classification which is being continuously used in landscape research and planning is not free from drawbacks as it is showing a high degree of inner variability despite even detailed classification schemes and hierarchical levels being considered. We are not claiming at dismissing crisp classification, but we suggest taking problems into account which derive from a crisp view of ecological entities being mapped. Since habitats are expected to gently and continuously vary rather than abruptly change within a landscape. 


\section{REFERENCES}

[1] Acosta, A., Carranza, M.L., Izzi, C.F. (2005): Combining land cover mapping of coastal dunes with vegetation. - Applied Vegetation Sciences 8: 133-138.

[2] Arbia, G., Griffith, D.A., Haining, R.P. (1998): Error propagation modelling in raster GIS; overlay operations. - Intern. J. of Geographical Information Sciences 12: 145-167.

[3] Arrell, K.E., Fisher, P.F., Tate, N.J., Bastin, L. (2007): A fuzzy c-means classification of elevation derivatives to extract the morphometric classification of landforms in Snowdonia, Wales. - Computational Geosciences 33: 1366-1381.

[4] Bartholomé, E., Belward, A.S. (2005): GLC2000: a new approach to global land cover mapping from earth observation data. - International Journal of Remote Sensing 26: 1959-1977.

[5] Bossard, M., Feranec, J., Otahel, J. (2000): CORINE land cover technical guide Addendum 2000. Technical report no.40. - European Environment Agency, Copenhagen.

[6] Burrough, P.A., McDonnell, R.A. (1998): Principles of Geographic Information Systems. - Oxford University Press, Oxford.

[7] Butler, B.J., Swenson, J.J., Alig, R.J. (2004): Forest fragmentation in the Pacific Northwest: quantification and correlations. - Forest Ec. and Management 189: 363-373.

[8] Chiarucci, A., Bonini, I. (2005): Quantitative floristics as a tool for the assessment of plant diversity in Tuscan forests. - Forest Ecology and Management 212: 160-170.

[9] Chiarucci, A., De Dominicis, V., Wilson, J.B. (2001): Structure and floristic diversity in permanent monitoring plots in forest ecosystems of Tuscany. - Forest Ecology and Management 141: 201-210.

[10] Eastman, R. (2006): Idrisi Andes guide to GIS and image processing. - Clark University, Worcester.

[11] EEA. (2005a): IMAGE2000 and CLC2000. Products and Methods CORINE Land Cover Updating for the year 2000. - European Environment Agency, Copenhagen, Denmark.

[12] EEA. (2005b): CORINE Land Cover: How to analyze changes. Internal report. European Environment Agency, Copenhagen, Denmark.

[13] Fisher, P. (2000): Sorites paradox and vague geogr. - Fuzzy Sets and Syst.113: 7-18.

[14] Gopal, S., Woodcock, C.E. (1994): Theory and methods for accuracy assessment of thematic maps using fuzzy sets. - Photogram. Engin. and Remote Sensing 60: 181-188.

[15] Hoekstra, J.M., Boucher, T.M., Ricketts, T.H., Roberts, C. (2005): Confront a biome crisis: global disparities of habitat loss and protection. - Ecology Letters 8: 23-29.

[16] Jelinski, D.E., Wu., J. (1996): The modifiable areal unit problem and implications for Landscape Ecology. - Landscape Ecology 11: 129-140.

[17] Johnson, D.D., Howarth, P.J. (1987): The effects of spatial resolution on land cover/land use theme extraction from airborne digital data. - Can. J. of Remote Sensing 13: 68-75.

[18] Kepner, W.G., Watts, C.J., Edmonds, C.M., Maingi, J.K., Marsh, S.E., Luna, G. (2000): A landscape approach for detecting and evaluating change in a semi-arid environment. Environmental Monitoring Assessment 64: 179-195.

[19] La Sorte, F.A., McKinney, M.L. (2006): Compositional similarity and the distribution of geographical range size for assemblages of native and non-native species in urban floras. - Diversity and Distribution 12: 679-686.

[20] Laba, M., Downs, R., Smith, S., Welsh, S., Neider, C., White, S., Richmond, M., Philpot, W., Baveye, P. (2008): Mapping invasive wetland plants in the Hudson River National Estuarine Research Reserve using Quickbird satellite imagery. - Remote Sensing of Environment 112: 286-300.

[21] Maselli, F., Conese, C., De Filippis, T., Norcini, S. (1995): Estimation of forest parameters through fuzzy classification of TM data. - Geosciences and Remote sensing 33: 77-84.

[22] McRoberts, R.E., Tomppo, E.O. (2007): Remote sensing support for national forest inventories. - Remote Sensing of Environment 110: 412-419.

APPLIED ECOLOGY AND ENVIRONMENTAL RESEARCH 8(1): 39-50. http://www.ecology.uni-corvinus.hu • ISSN 15891623 (Print) • ISSN 17850037 (Online) (C) 2010, ALÖKI Kft., Budapest, Hungary 
[23] Nagendra, H. Rocchini, D. (2008): Satellite imagery applied to biodiversity study in the tropics: the devil is in the detail. - Biodiversity and Conservation 17: 3431-3442.

[24] Neumann, K., Herold, M., Hartley, A., Schmullius, C. (2007): Comparative assessment of CORINE2000 and GLC2000: Spatial analysis of land cover data for Europe. International Journal of Applied Earth Observation 9: 425-437.

[25] Oren, R., Ellsworth, D.S., Johnsen, K.H., Phillips, N., Ewers, B.E., Maier, C., Schafe, K.V.R., McCarthy, H., Hendrey, G., McNulty, S.G., Katul, G.G. (2001): Soil fertility limits carbon sequestration by forest ecosystems in a $\mathrm{CO}_{2}$-enriched atmosphere. - Nature 411: 469-472.

[26] Palmer, M.W., Earls, P., Hoagland, B.W., White, P.S., Wohlgemuth, T. (2002): Quantitative tools for perfecting species lists. - Environmetrics 13: 121-137.

[27] Pekkarinen, A., Reithmaier, L., Strobl, P. (2009): Pan-European Forest/Non-Forest mapping with Landsat ETM+ and CORINE Land Cover 2000 data. - ISPRS Journal of Photogrammetry and Remote Sensing, in press.

[28] Perry, D.A. (1994): Forest Ecosystems. - Johns Hopkins University Press, Baltimore.

[29] R Development Core Team (2007): R: A language and environment for statistical computing. - R Foundation for Statistical Computing, Vienna.

[30] Ricotta, C., Celesti-Grapow, L., Avena, G., Blasi, C. (2001): Topological analysis of the spatial distribution of plant species richness across the city of Rome (Italy) with the echelon approach. - Landscape Urban Planning 57: 69-76.

[31] Rocchini, D. (2007): Distance decay in spectral space in analysing ecosystem $\beta$ diversity. - International Journal of Remote Sensing 28: 2635-2644.

[32] Rocchini, D., Andreini Butini, S., Chiarucci, A. (2005): Maximizing plant species inventory efficiency by means of remotely sensed spectral distances. - Global Ecology and Biogeography 14: 431-437.

[33] Rocchini, D., Perry, G.L.W., Salerno, M., Maccherini, S., Chiarucci, A. (2006): Landscape change and the dynamics of open formations in a natural reserve. - Landscape and Urban Planning 77: 167-177.

[34] Rocchini, D., Ricotta, C. (2007): Are landscapes as crisp as we may think? - Ecological Modelling 204: 535-539.

[35] Rogerson. P.A. (2001): Statistical Methods for Geography. - Sage Publications, London, Thousand Oaks, New Delhi.

[36] Romero-Calcerrada, R., Perry, G.L.W. (2004): The role of land abandonment in landscape dynamics in the SPA Encinares del rio Alberche y Cofio, Central Spain, 19841999. - Landscape and Urban Planning 66: 217-232.

[37] Small C. (2004): The Landsat ETM+ spectral mixing space. - Remote Sensing of Environment 93: 1-17.

[38] Sohngen, B., Mendelsohn, R., Sedjo, R. (1999): Forest management, conservation, and global timber markets. - American Journal of Agricultural Economics 81: 1-13.

[39] Stohlgren, T.J., Coughenour, M.B., Chong, G.W., Binkley, D., Kalkhan, M.A., Schell, L.D., Buckley, D.J., Berry, J.K. (1997): Landscape analysis of plant diversity. Landscape Ecology 12: 155-170.

[40] Wilcox, B.A., Murphy, D.D. (1985): Conservation strategy: the effects of fragmentation on extinction. - American Naturalist 125: 879-887.

[41] Wulder, M. (1998): Optical remote-sensing techniques for the assessment of forest inventory and biophysical parameters. - Progress in Physical Geography 22: 449-476.

[42] Zadeh, L. (1978): Fuzzy sets as a basis for a theory of possibility. - Fuzzy Sets and Systems 1: 3-28.

[43] Zadnik Stirn, L. (2006): Integrating the fuzzy analytic hierarchy process with dynamic programming approach for determining the optimal forest management decisions. Ecological Modelling 194: 296-305.

[44] Zar, J.H. (1996): Biostatistical Analysis. - Englewood Cliffs, New Jersey Prentice Hall.

APPLIED ECOLOGY AND ENVIRONMENTAL RESEARCH 8(1): 39-50. http://www.ecology.uni-corvinus.hu • ISSN 15891623 (Print) • ISSN 17850037 (Online) (C) 2010, ALÖKI Kft., Budapest, Hungary 